\title{
Direitos humanos, valores morais e educação libertadora: diálogos para a construção da autonomia na escola
}

\author{
Human rights, moral values, and libertarian education: dialogues for the \\ construction of autonomy in school
}

\author{
Rita Melissa Lepre ${ }^{1}$ \\ Isabel Cristina de Campos $^{2}$ \\ Eduardo Silva Benetti ${ }^{3}$ \\ Matheus Estevão Ferreira da Silva ${ }^{4}$
}

\section{Resumo}

O presente artigo tem como objetivo compartilhar um estudo teórico-metodológico relacionado às possíveis aproximações entre o trabalho pedagógico voltado à Educação em Direitos Humanos, à Educação em Valores na escola e à Educação Libertadora em Paulo Freire. A Educação em Direitos Humanos, a Educação em Valores e a Educação Libertadora, ainda que possuam especificidades epistemológicas e metodológicas, convergem para o objetivo comum de almejar a autonomia moral dos sujeitos, para que a partir de raciocínios e juízos morais mais elevados, baseados em princípios universais, seja possível a construção de uma sociedade mais justa e democrática.

Palavras-chave: Autonomia. Educação em Direitos Humanos. Educação em Valores. Educação Libertadora.

\begin{abstract}
This article aims to share a theoretical-methodological study related to possible approaches between the pedagogical work aimed at Education in Human Rights, Education in Values at school and Liberating Education in Paulo Freire. Education in Human Rights, Education in Values and Liberating Education, even though they have epistemological and methodological specificities, converge to the common objective of aiming for the moral autonomy of subjects, so that, it is possible to build a fairer and more democratic society from higher moral reasoning and judgments, based on universal principles
\end{abstract}

\footnotetext{
${ }_{1}^{1}$ Psicóloga, Mestre e Doutora em Educação. Especialista em Neuropsicologia. Livre-Docente em Psicologia da Educação.Docente Associada da Universidade Estadual Paulista - UNESP, na Faculdade de Ciências, Departamento de Educação - Campus Bauru. Email: melissa.lepre@unesp.br

${ }^{2}$ Mestra em Docência para Educação Básica - UNESP/BAURU, Docente Pedagogia Instituto Federal do Paraná - Campus Jacarezinho. Email: isabel.campos@ifpr.edu.br

${ }^{3}$ Mestrando em Docencia para Educação Básica - UNESP/BAURU, formado em educação física e pedagogia, docente da rede municipal de Catanduva/SP. Email: eduardo.benetti@unesp.br

${ }^{4}$ Mestrando em Educação e Pedagogo pela Faculdade Filosofia e Ciências (FFC), UNESP, Campus de Marília, e graduando em Psicologia pela Faculdade de Ciências e Letras (FCL), UNESP, Campus de Assis. Email: matheus.estevaoz@hotmail.com
} 
Keywords: Autonomy. Human Rights Education. Education in Values. Liberating Education.

\section{Introdução}

O grupo de estudos e pesquisas em desenvolvimento moral e educação (GEPEDEME), constituído no ano de 2014, tem como objetivo estudar e produzir pesquisa científica sobre temas relacionados ao desenvolvimento moral e suas relações com a Educação, com foco na educação em valores na escola. Em sua composição tem alunos de graduação, mestrandos, doutorandos e pós-doutorandos em Educação e Psicologia que pesquisam diferentes temas voltados à construção da autonomia moral. Dentre as muitas reflexões, pesquisas e atividades realizadas junto ao GEPEDEME pretendemos compartilhar, neste artigo, um estudo teórico-metodológico relacionado às possíveis aproximações entre o trabalho pedagógico voltado à Educação em Direitos Humanos (EDH), à Educação em Valores na escola e à educação libertadora em Paulo Freire.

Partiremos da concepção de que a EDH, a Educação em Valores e a Educação Libertadora de Paulo Freire almejam a autonomia moral dos sujeitos, entendendo autonomia como a possibilidade de reflexão sobre regras que sejam boas para todos, pautadas em princípios universais, como o direito à vida e à liberdade, tendo o respeito como base. Também partiremos da concepção de que para que a autonomia seja alcançada é necessário um trabalho pedagógico intencional e planejado voltado a esse fim, uma vez que a moralidade não é algo inato, sendo construída durante toda a vida por meio das interações sociais e da educação moral ou em valores.

Segundo Buxarrais (1997), há três modelos distintos de Educação Moral que diferem entre si quanto aos objetivos, métodos e filosofia de trabalho. O primeiro são os modelos de educação baseados em valores absolutos, nos quais há uma visão de mundo composta por valores e normas de conduta indiscutíveis e imutáveis. Nesses modelos a educação moral é ligada à reprodução de modelos socialmente desejáveis. O segundo são os modelos de educação moral baseados em valores relativos, nos quais os valores e normas de conduta são concebidos a partir de critérios totalmente subjetivos, sendo as decisões de ação pessoais e não coletivas. O terceiro são os modelos de educação em valores baseados na construção racional e autônoma de valores, objetivando a construção da moralidade do sujeito (juízo, raciocínio, personalidade, competência), considerando a coletividade e o bem comum. As visões teóricas que buscaremos relacionar se inserem no terceiro grupo, uma vez que objetivam a construção participativa da autonomia do sujeito, que é inserido social e culturalmente em uma sociedade plural e multifacetada. 


\section{A Educação em Direitos Humanos}

A educação brasileira assume, contemporaneamente, papel imprescindível na concretização dos preceitos sustentados pelos/nos direitos humanos - principalmente de defesa da dignidade humana -, pois, segundo Candau et. al. (2013, p. 33), “[...] o crescente interesse pelos direitos humanos e suas constantes violações hoje, na sociedade brasileira, desafia-nos a promover uma educação que contribua com a compreensão, a conquista e a vivência desses direitos no nosso meio". Assim, uma vez reconhecidas as potencialidades da Educação para tal pretensão, o sistema educacional do país passou a aspirar e contemplar legalmente uma proposta de educação que se volte aos direitos humanos.

Considerando o grande espectro que é a Educação e o sistema educacional brasileiro, da Educação Básica à Educação Superior, segundo Silva (2012, p. 44) a Educação em Direitos Humanos tem “a escola de educação básica um espaço privilegiado pelas contribuiç̧̃̃es que ela pode oferecer [...]. A defesa intransigente da educação como direito humano é condição de exercício de cidadania, de conquista e ampliação de novos direitos". Então como ressaltado, a Educação é condição necessária, um direito sine qua non, para que os preceitos dos direitos humanos, os quais a EDH consequentemente carrega, concretizem-se.

No Brasil, a Educação em Direitos Humanos (EDH), política pública educacional em vigência no país, encontra-se instituída desde o ano de 2006, com a publicação do Plano Nacional de Educação em Direitos Humanos (PNEDH) (BRASIL, 2007), que foi atualizado em 2013 para uma segunda versão (BRASIL, 2013), assim como com a publicação das Diretrizes Nacionais para a Educação em Direitos Humanos (DNEDHs) no ano de 2012 (BRASIL, 2012), a partir dos quais a EDH passa a ter força de lei. Assim, a EDH é uma perspectiva de Educação que tem seu desenvolvimento previsto a todos os níveis de ensino, da Educação Básica à Educação Superior, nas modalidades formal e não-formal.

Essa sua instituição é tanto resultado do cumprimento do compromisso firmado pelo Brasil, até então signatário de todos os documentos internacionais de direitos humanos elaborados e propostos pela Organização das Nações Unidas (ONU), quanto resultado da cobrança dos movimentos sociais e da sociedade civil organizada, "cobrando e reivindicando seus direitos dentro da realidade nacional, caracterizada, historicamente, por desigualdades de diferentes naturezas e pela marginalização de determinados grupos sociais" (SILVA; BRABO; MORAIS, 2017, p. 1266). E a instituição da EDH também se destaca como uma das principais articulações do Estado para a garantia do ensino e discussão dos direitos humanos e aspectos relacionais no sistema educacional brasileiro.

Contudo, essa articulação do Brasil veio atrasada em relação aos demais paísesmembros da ONU e signatários dos tratados e documentos internacionais por ela propostos, que desde o período pós-guerra discutiam o desafio de sustentar uma Educação comprometida com os direitos humanos, a paz e a dignidade entre as nações para as próximas gerações, comumente referida como educação para a paz (SOUZA, 
2007; RAYO, 2004). Esse atraso se deu em razão do período da ditatura militar, de difícil cumprimento e contemplação dos direitos humanos, e a Educação em Direitos Humanos só pôde ser contemplada anos depois, após o processo de redemocratização do país.

Se a constituição da EDH, como uma política global (RAYO, 2004), apresentou desenvolvimento gradual e tardio até chegar ao Brasil, sua constituição como proposta e projeto educacional, embora já manifestada em períodos anteriores, é concebida sob maior impacto - e interesse em comum por parte das nações - durante o reconhecimento jurídico e social dos direitos humanos. Reconhecimento que ocorre no período moderno pós-guerra do final da primeira e início da segunda metade do século XX, marcado pelas mazelas acometidas com a Segunda Guerra Mundial.

Dessa forma, a EDH, conforme é conhecida hoje, foi formada em meio à discussão, realizada em diferentes instâncias e já a datar em períodos anteriores ao pós-guerra no século XX, acerca do papel e da necessidade de uma Educação para a superação das violações históricas de direitos, da exclusão de sujeitos e grupos sociais, violências, injustiça social, preconceitos, discriminação, etc., então resultante na modelação de uma nova perspectiva de Educação, a educação para a paz, que [...] há mais de 80 anos, vem sendo discutida e estudada por educadores, filósofos, sociólogos, antropólogos e psicólogos de diversos países, sob ênfases variadas" (SOUZA, 2007, p. 134).

Um dos marcos teóricos na discussão dessa Educação emancipatória, voltada à consolidação da paz, é o livro Educação e emancipação do filósofo alemão Theodor W. Adorno (1995). Para Adorno (1995), a Educação deve ter por objetivo principal a emancipação humana, a qual ausenta as pessoas das iniquidades historicamente afirmadas e cria condições para vida livre e consciente em sociedade. Outro importante marco é o livro Pedagogia do oprimido do educador e filósofo Paulo Freire (2005), que propõe uma Pedagogia com uma nova forma de relacionamento entre professor, estudante e sociedade.

Como discute Rayo (2004), principalmente com a fundação da Organização das Nações Unidas para a Educação, a Ciência e a Cultura (UNESCO), órgão executivo da ONU, foram priorizadas as ações referentes à Educação numa dimensão global, sendo essa organização responsável pela publicação de vários documentos que "[...] contribuíram decisivamente para a definição da Educação para a Paz na orientação pedagógica, de suas linhas básicas de atuação e intervenção educativa” (RAYO, 2004, p. 64). Assim, com origens na prerrogativa de educação para paz, a EDH "toma corpo, fortalece-se na crescente manifestação da organização e países-membros a respeito dessa educação do ponto de vista burocrático e, a partir da década de 1970, desenvolve-se oficialmente a educação em direitos humanos" (SILVA; BRABO; MORAIS, 2017, p. 1265).

${ }^{5}$ Os direitos humanos são independentes e indivisíveis (BENEVIDES, 2000), portanto, sem o direito à Educação, os demais direitos não se realizam, e vice-versa, além da Educação se verificar como uma das principais formas para a concretização dos direitos humanos e de seus preceitos. 
Dentro da proposta da Educação em Direitos Humanos e dos vários aspectos por ela previstos, Benevides (2000, online) elenca três pontos essenciais para serem cumpridos na formação daqueles(as) que passam por ela, sendo o terceiro deles se tratando da: "[...] inculcação de valores, para atingir corações e mentes e não apenas instrução, meramente transmissora de conhecimentos". Essas três dimensões fundantes da $E D H$, conforme podem ser denominadas, também são previstas explicitamente no texto do próprio PNEDH (BRASIL, 2007, p. 32), principalmente no que tange ao seu desenvolvimento no âmbito da escola de Educação Básica:

\begin{abstract}
A educação em direitos humanos deve ser promovida em três dimensões: a) conhecimentos e habilidades: compreender os direitos humanos e os mecanismos existentes para a sua proteção, assim como incentivar o exercício de habilidades na vida cotidiana; b) valores, atitudes e comportamentos: desenvolver valores e fortalecer atitudes e comportamentos que respeitem os direitos humanos; c) ações: desencadear atividades para a promoção, defesa e reparação das violações aos direitos humanos.
\end{abstract}

Sobre isso, Maciel (2018), por meio da técnica de Análise do Conteúdo, identificou os três aspectos descritos por Benevides (2000), só que agora analisando os documentos oficiais nacionais da Educação em Direitos Humanos (as duas versões do PNEDH e as DNEDH), nomeando esse terceiro aspecto de uma: “[...] educação em direitos humanos voltada para uma perspectiva de valores, práticas sociais e atitudes" (MACIEL, 2018, p. 125).

Além de Benevides (2000), outros autores da literatura (SILVA, 2010; 2012) compartilham dessa mesma interpretação sobre o processo formativo pretendido pela EDH, sendo então entendida como um "processo sistemático e multidimensional com vistas à formação de sujeitos de direitos" e, dessa forma, "articulando as seguintes dimensões: a apreensão de conhecimentos específicos da área; a afirmação de valores, comportamentos e atitudes na defesa intransigente dos direitos de todos; a formação de uma consciência cidadã" (SILVA, 2012, p. 41), sendo esse último responsável por possibilitar a concretização materialize de ações, de práticas coletivas que possam gerar instrumentos de ampliação e fortalecimento dos direitos humanos.

Nesse sentido, Silva (2010) também ressalta que, nessa concepção, a Educação em Direitos Humanos não se limita à contextualização e à explicação das variáveis sociais, econômicas, políticas e culturais que cerceiam a vida humana, mas que, ainda que imprescindíveis, vai além disso. Assim, faz parte dessa Educação apreender os conteúdos que "dão corpo" a essa área, tais como da História, acerca dos processos e evolução das conquistas e das violações dos direitos, as legislações, pactos e acordos que dão sustentabilidade e garantia aos direitos humanos. No entanto, esses conteúdos devem ser relacionados ao desenvolvimento de valores e a comportamentos éticos: "na 
perspectiva de que o ser humano é sempre incompleto em termos da sua formação. Por ter essa incompletude enquanto ser social, datado, localizado, o ser humano tem permanentemente necessidade de conhecer, construir e reconstruir regras de convivência em sociedade" (SILVA, 2010, p. 49).

Dessa forma, é nítido que, entres os vários aspectos previstos pela Educação em Direitos Humanos, encontra-se um projeto de educação em valores como ponto essencial para seu cumprimento e efetivação, seja como política pública, seja como projeto de Educação demandado historicamente. Educar em direitos humanos também é educar em valores. É, essencialmente, "a formação de uma cultura de respeito à dignidade humana através da promoção e da vivência dos valores da liberdade, da justiça, da igualdade, da solidariedade, da cooperação, da tolerância e da paz" (BENEVIDES, 2000, online).

Com base nisso, a seguir, aprofundamo-nos nas bases para uma educação em valores na escola e, em seguida, propomos a abordagem freiriana de educação libertadora como uma alternativa teórico-metodológica para fundamentar essa proposta de Educação.

\section{A Educação em valores na escola}

Paulo Freire (2005) reitera que a inconclusão é uma condição humana que direciona o homem na busca pelo conhecimento de si e do mundo, vocação ontológica essa que permite aos sujeitos (re)escrever suas histórias e formar-se permanentemente. Educar é substantivamente formar, determinação que exige da prática docente um alto nível de responsabilidade ética. O autor alerta que transformar a experiência educativa em puro treinamento técnico é amesquinhar o que há de fundamentalmente humano no exercício educativo: o seu caráter formador. Enfatiza que se se respeita a natureza do ser humano, o ensino dos conteúdos não pode dar-se alheio à formação moral do educando. Apesar disso, a formação inicial ou continuada do educador que se apoiam na racionalidade técnica ocupa posição hegemônica, estrutura essa que contribui para pouca mudança na ordem social injusta.

Ao analisar modelos de educação em valores do passado percebem-se formas educativas tradicionais, conservadoras que se assemelhavam a educação bancária (FREIRE, 2005) ao depositar, transferir, transmitir valores, conhecimentos e inculcar ideologias. No período ditatorial 1964-1985, por exemplo, no rol de disciplinas escolares foi oferecida a Educação Moral e Cívica visando transmitir um conjunto de atitudes e comportamentos representativos de um ideal de "ordem" estabelecido pelo governo, além de servir como mecanismo de reprodução e legitimação do regime militar, sua base apoiava-se nas tradições nacionais e estava impregnada de pensamento conservador (ROSTAS; ABREU, 2016). Nota-se também que o autoritarismo não apostou na formação de educadores e educandos, mas no material e na avaliação para certificar-se de que suas ordens eram cumpridas. Sabe-se que a educação bancária propõe a cultura do silêncio e a 
obediência cega, condições propícias a manutenção de estágios primitivos da heteronomia.

Com a chegada da democracia o momento se fez oportuno para a reconstrução da sociedade e a educação, não por menos, a propulsora de transformações. Cauteloso Freire (2005, p.74) alerta que "a educação não é a chave para a transformação, mas é indispensável. A educação sozinha não faz, mas sem ela também não é feita a cidadania” O novo contexto exigia políticas educacionais coerentes com o novo sistema e a redefinição de novas formas de atuação.

A educação moral, estigmatizada devido seu caráter repressor, foi banida dos currículos, mas certamente continuou no escopo do trabalho docente, em muitos casos pautada na imposição heterônoma de valores, em outros em sua relativização e no subjetivismo. Paralelo a isso se erguiam concepções que se apoiavam na construção racional e autônoma de princípios, valores e normas no intuito de facilitar a convivência em sociedades abertas e plurais e a viver uma vida justa e solidária (PUIG, 1998).

Com a promulgação da Constituição Federal (BRASIL, 1988) e com a Lei de Diretrizes e Bases da Educação Nacional (BRASIL, 1996) houve grande preocupação com o pleno desenvolvimento da pessoa e seu preparo para o exercício da cidadania, preocupações essas que refletiram na produção de diretrizes para oferta de educação integral, os Parâmetros Curriculares Nacionais (PCN) (BRASIL,1997) foram um exemplo disso, uma de suas categorias de conteúdo, os atitudinais, envolviam a abordagem de valores, normas e atitudes, pontos que estavam presentes nos documentos, tanto de áreas, quanto de Temas Transversais. Propunham trabalhos interdisciplinares voltados para temáticas como ética, pluralidade cultural, orientação sexual, meio ambiente e saúde. Esses documentos também realçavam a importância da formação inicial e continuada do professor. Freire (2005) já indicava que a formação docente permanente, deveria ser pensada para refletir, reconstruir, refazer e reinventar a práxis pedagógica existente, por sua vez os PCN afirmavam em seus princípios e fundamentos que:

\begin{abstract}
Na sociedade democrática, ao contrário do que ocorre nos regimes autoritários, o processo educacional não pode ser instrumento para a imposição, por parte do governo, de um projeto de sociedade e de nação. Tal projeto deve resultar do próprio processo democrático, nas suas dimensões mais amplas, envolvendo a contraposição de diferentes interesses e a negociação política necessária para encontrar soluções para os conflitos sociais (BRASIL, 1997. p.27).
\end{abstract}

Com a nova organização social, fruto de muita luta e trabalho o campo educacional foi se redesenhando para atender as novas demandas. Em 2010, o Ministério da Educação, possibilita à rede pública de ensino a inserção de uma perspectiva de educação centrada no respeito aos direitos humanos de modo a favorecer a formação da cidadania ativa. Políticas públicas dão ênfase a formação integral e o desenvolvimento pleno da cidadania, tal como as Diretrizes Curriculares Nacionais Gerais para a Educação Básica (BRASIL, 2010) que delegam à educação a responsabilidade de proporcionar o 
desenvolvimento humano na sua plenitude em caráter emancipador e libertador e afirma a educação em direitos humanos como um dos caminhos. Conforme Kohlberg (apud LA TAILLE, 2006. p.21), “os Direitos Humanos não são apenas um sistema moral entre outros, mas o sistema para o qual tende a evolução moral dos indivíduos e das sociedades". Nota-se que essas legislações e estudos, de certa forma, comungam dos mesmos ideais da Pedagogia Libertadora de Paulo Freire, pois levam em consideração a realidade brasileira e aspiram a sua transformação.

Percebe-se na Educação Moral Ativa, na Educação em Direitos Humanos, na Educação para Paz e outras com nomenclaturas diversas, que tem como premissa educar em valores humanos, universalmente aceitáveis, que essas podem contribuir com à educação libertadora de Paulo Freire, pois compartilham da máxima que a "existência humana não pode ser muda, silenciosa, nem tampouco pode nutrir-se de falsas palavras, mas de palavras verdadeiras, com que os homens transformam o mundo. Existir, humanamente, é pronunciar o mundo, é modificá-lo." (FREIRE, 1987, p.44). Libertação e emancipação conquistam-se com autonomia do educador e do educando condições essas necessárias para o real exercício da cidadania numa sociedade democrática.

A educação moral supõe orientar-se autonomamente em situações de conflito de valores, não se pode catalogá-la de prática reprodutora ou inculcadora de valores; seria, provavelmente, melhor entendê-la como lugar de mudança e de transformação pessoal e coletiva, como lugar de emancipação. Se por outro lado, a educação moral supõe orientar-se racional e dialogicamente em situações de conflitos de valores, não se pode catalogá-la de prática individualista ou subjetivista. (PUIG, 1998. p.18)

Atualmente ao definir suas competências, a Base Nacional Comum Curricular (BNCC) reconhece que a "educação deve afirmar valores e estimular ações que contribuam para a transformação da sociedade, tornando-a mais humana, socialmente justa [...]" (BRASIL, 2017. P.8), mas praticamente não apresenta propostas de trabalho neste sentido. Incumbe aos sistemas de ensino municipais e estaduais a tarefa de incorporar aos currículos e às propostas pedagógicas a abordagem de temas contemporâneos que afetam a vida humana em escala local, regional e global, preferencialmente de forma transversal e integradora. O documento também propõe formação inicial e continuada dos professores para alinhá-las à BNCC (BRASIL, 2017, p.20).

Estudos (PUIG, 1998) mostram que sociedades democráticas e pluralistas exigem intervenções educativas ativas, pois essas favorecem a evolução moral. O modelo proposto se afasta dos que se baseiam em valores absolutos e relativos e se aproxima de princípios de autonomia e razões dialógicas, sem violentar as crenças plurais dos homens e mulheres, seus fundamentos tornam possíveis valores como a crítica, a abertura para com os demais e o respeito aos direitos humanos. Já Freire (2005) avisa que a solidariedade social e política de que precisamos para construir a sociedade menos feia e 
menos arestosa, em que podemos ser mais nós mesmos, tem a formação democrática uma prática de real importância.

Neste momento pode-se dizer que a sociedade demonstra uma tendência de crise de valores talvez devido à ausência de legitimação moral ou quem sabe se encontre em processo de transformação dos valores, mudando de interpretação, ou até por estar sendo regida pela boa e velha moral dos antepassados (LA TAILLE, 2009). De qualquer modo, sem sombra de dúvidas, é importantíssimo realizar trabalhos na escola que envolvam reflexão e construção de valores, em formação inicial e continuada para os educadores e para os educandos. É urgente apoiar-se em estudos que visam a emancipação, a autonomia moral, a educação integral, a educação em direitos humanos ou outras formas de atuação para educação em valores éticos e universais que são indispensáveis a convivência. Uma das propostas é a Educação libertadora de Paulo Freire que pode ser construída, pois "a liberdade amadurece no confronto com outras liberdades na defesa de seus direitos em face da autoridade dos pais, do professor, do Estado" (FREIRE, 2005, p.107). A escola como palco ideal deve oferecer uma pedagogia da autonomia centrada em experiências estimuladoras da decisão e da responsabilidade, vale dizer, em experiências respeitosas da liberdade.

\section{A Educação libertadora em Paulo Freire}

Pensar em Paulo Freire e não o correlacionar a uma luta educacional contra hegemônica e que tem em um de seus alicerces mais fortes, à formação permanente de educadores para uma educação libertadora, é praticamente impossível. Freire tem sua história marcada pela dedicação em levar uma proposta educativa que forme educadores para uma prática crítica-reflexiva e que acima de tudo, possam fazer a diferença em seu contexto social.

Portanto, a educação e tudo o que a compreende enquanto currículo, estrutura, formação, políticas educacionais, jamais podem ser neutros, aliás, Freire já afirmava a impossível neutralidade da educação, além de afirmar ao longo de suas obras que educar é um ato político, ou melhor, não existe educação que não seja política, todavia, não quer dizer partidária, mas sim, possibilitar com que os educandos possam fazer parte da sociedade de forma atuante e não mera representação populacional. Nas próprias palavras do autor:

A politicidade da educação demanda veementemente que o professor e a professora se assumam como políticos, que se descubram no mundo como um político e não como um puro técnico ou um sábio, porque também o técnico e o sábio, são substantivamente políticos. (FREIRE, 2020, p.35)

Dessa forma, o educador também se encontra num papel central de ator na construção social libertadora. Paulo Freire define esse educador comprometido com a 
mudança como educador progressista, aquele que sabe de seu papel político, que sabe que é necessária não somente a reflexão, passiva em si, mas uma ação crítica que passe para o agir, que modifique a práxis educativa e social e que possibilite a assunção de valores éticos para a construção de uma sociedade menos desigual.

Dessa forma, a construção de uma sociedade menos desigual se faz pela ascensão do menos favorecido à patamares mais elevados, Freire (2015) acreditava que é através de uma educação que não seja passiva, ingênua é que seria construído um caminho possível para a mudança desse paradigma:

De uma educação que tentasse a passagem da transitividade ingênua à transitividade crítica, somente como poderíamos, ampliando e alargando a capacidade de captar os desafios do tempo, colocar o homem brasileiro em condições de resistir aos poderes da emocionalidade da própria transição. Armálo contra a força dos irracionalismos, de que era presa fácil na emersão que fazia, em posição transitivante ingênua. (FREIRE, p.89, 2015)

Freire transformou-se em um símbolo de luta, seu pensamento hoje estudado em muitos países, assustam grupos conservadores, que apoiados pela mídia, subvertem as lutas contra hegemônicas, gerando práticas que, por não serem reflexivas e críticas, acabam sendo aceitas pela sociedade (SAUL; SAUL, 2016).

A mercantilização educacional, muitas vezes financiada pelos governos, gera uma ruptura que vai de encontro com o pensamento freiriano, visando lucros e controlando a educação e mais, a forma com que os educadores devem pensar. Assim, quando há uma proposta educacional que rompe com o modelo dominante, não raro, são atacados por diversos órgãos, quando não, pelos próprios educadores reacionários.

Para esses educadores, Freire tem uma denominação assertiva,

(...) Para o professor reacionário, a educação [...] têm a ver com a educação da classe dominante, lutando para preservar condições materiais da sociedade que aí está, para que a classe dominante, reproduzindo sua ideologia e seu poder através da educação, preserve o seu poder político e econômico. (FREIRE, 2020, p.36)

Logo, para a classe dominante e para os educadores reacionários, uma educação realmente comprometida com a reconstrução da sociedade, através de atores políticos conscientes de seu papel social, não é interessante, portanto, deve ser combatido, denegrido.

A construção de uma educação libertadora só será possível na substituição ou reinvenção de práticas "bancárias", tão interiorizadas nos processos formativos, sejam esses aos educadores, ou os que são transmitidos aos educandos:

E educação institucionalizada, especialmente nos últimos 150 anos, serviu - no seu todo- ao propósito de não só fornecer os conhecimentos e o pessoal necessário à máquina produtiva em expansão do sistema do capital, como também gerar e transmitir um quadro de valores que legitima os interesses 


\section{-Revista de Iniciação à Docência, v. , n. , 2021- Publicação: dezembro, 2021 - ISSN 2525-4332}

dominantes, como se não pudesse haver nenhuma alternativa à gestão da sociedade, seja na forma "internalizada" (isto é, pelos indivíduos devidamente "educados" e aceitos) ou através de uma dominação estrutural e uma subordinação hierárquica e implacavelmente impostas. (MÉSZÁROS, 2008, p.35)

Freire (2005), ao pensar em uma educação libertadora, anteviu as amarras de uma precarização educacional e as consequências aos grupos sociais menos favorecidos, bem como o controle e manipulação através das classes dominadoras, por isso, Freire e tão combatido até os dias de hoje. A possibilidade de o poder manipulativo sair das mãos de quem define o quê, quando, como e para quê deve se estudar, assusta e mobiliza forças para afastar da formação docente, o pensamento que possa reinventar constantemente a práxis educacional, consequentemente, possibilitando a reestruturação de ferramentas necessárias para sobrepujar a desigualdade social. Nessa mesma perspectiva que Freire desconstrói a fala "a educação pode tudo", ele nos mostra que a educação não pode e é por isso mesmo que ela tem condições de pode algo e ainda mais, tece severas críticas à passividade dos educadores em não discutir as possibilidades educacionais,

\section{O grande problema do educador não é discutir se a educação pode ou não pode, mas discutir onde pode, como pode e com quem pode, quando pode. É reconhecer limites que sua prática impõe. É reconhecer que há espaços possíveis que são políticos, há espaços institucionais e extrainstitucionais a serem ocupados pelas educadoras e pelos educadores, cujo sonho é transformar a realidade injusta que aí está, para que os direitos possam começar a ser conquistados e não doados. (FREIRE, 2020, p.39)}

Portanto, não pode haver inércia por parte do educador progressista, nem das práticas educacionais libertadoras, baseadas em um currículo que olhe para além da estrutura conteudista, mas para a formação humana, como parte de uma construção social e para uma formação docente permanente, que seja pensada para refletir, reconstruir, refazer e reinventar a práxis pedagógica existente.

Dessa forma, a articulação entre uma educação libertadora, que emancipa e possibilita o ser humano agir na sociedade e o educador deve transcender o mero campo das ideias, sem isso, ainda permaneceremos ainda presos aos ditames daqueles que perpetuam e definem quais classes devem ser privilegiadas.

Logo, a educação deve ser algo que possa possibilitar uma visão crítica da realidade, bem como fornecer condições de agir nas mais variadas possibilidades, ou seja, agir politicamente na sociedade através de uma educação libertadora.

"Educação que lhe pusesse à disposição meios com os quais fosse capaz de superar a captação mágica ou ingênua de sua realidade, por uma dominantemente crítica" (FREIRE, 1967, p.113), assim, através da própria reflexão em Freire, reforçamos a necessidade de uma educação libertadora que afaste da população o obscurantismo e que possibilite cada vez mais que haja ações critico-reflexivas na sociedade e para a sociedade, tornando-a mais igual. Para tanto, a construção da autonomia moral dos sujeitos se faz necessária. 


\title{
Diálogos possíveis, conjecturas e proposições
}

Freire durante todo seu percurso como educador e até os dias atuais, propõe reflexões assertivas sobre o percurso educacional do Brasil e como a educação deve ser utilizada como ferramenta de ascensão social e, acima de tudo, possibilitar com que a sociedade tenha condições de refletir acerca daquilo que lhe é posto e por muitas vezes imposto, mas que deve ser tomado com olhares críticos e agir refletido. Uma luta contra a submissão das classes mais sofridas.

Através de seu pensamento, tão combatido na atualidade, podemos compreender o que é que a educação emancipadora deve possibilitar, ou seja, ter condições de não se sujeitar perante uma sociedade desigual, como podemos observar nesse excerto,

\begin{abstract}
Sentíamos - permitia-se a repetição - que era urgente uma educação que fosse capaz de contribuir para aquela inserção a que tanto temos nos referido. Inserção que, apanhando o povo na emersão que fizera com a "rachadura da sociedade", fosse capaz de promovê-lo da transitividade ingênua à crítica. Somente assim evitaríamos a sua massificação. (FREIRE, 1967, p.113)
\end{abstract}

A luta por uma educação libertadora e emancipadora, que se baseie em princípios fundamentais aos Direitos Humanos e que reconheça a importância da educação em valores passa pela construção da autonomia moral. Entendemos que a transformação social só será possível a partir de um movimento dialético que envolva a cultura, a política, a organização social e a construção do próprio indivíduo que pensa, sente e age.

Nesse sentido, é necessário que os sujeitos atinjam níveis mais elevados de raciocínio moral para que possam fazer julgamentos morais baseados em princípios universalizantes que possibilitem condutas virtuosas. Em seus estudos Kohlberg (1992) apontou que o raciocínio moral se desenvolve a partir das interações sociais e passa por três níveis: pré-convencional, convencional e pós-convencional.

O nível pré-convencional corresponde à perspectiva sócio-moral individual concreta, na qual ainda não há a percepção do caráter convencional das regras, que são, assim, externas ao eu, tidas como naturais ou como caprichos de autoridades. O nível convencional corresponde à perspectiva membro-dasociedade, em que o eu se identifica com as expectativas dos outros, e na qual há consciência quanto, e respeito, à convencionalidade das regras, já internalizadas, vistas como necessárias e decorrentes das relações de cooperação. Por fim, o nível pós-convencional corresponde à perspectiva precedente-à-sociedade (prior-to-society), em que o eu se diferencia das expectativas dos outros e, fazendo abstração do caráter convencional das regras, pode pensá-las em seu ideal, gerando princípios éticos próprios. (VENTURI, 1995, p.68).

Como vimos, os Direitos Humanos não são apenas um sistema moral entre outros, mas o sistema para o qual tende a evolução moral dos indivíduos e das sociedades. 


\section{Considerações Finais}

A educação para a autonomia na escola é aquela voltada para a superação da heteronomia do sujeito, que ocorre por meio de vivências e experiências nas quais o respeito, a justiça, a cooperação e a reciprocidade estejam presentes.

A Educação em Direitos Humanos, a Educação em Valores e a Educação Libertadora, ainda que possuam especificidades epistemológicas e metodológicas, convergem para o objetivo comum de almejar a autonomia moral dos sujeitos, para que a partir de raciocínios e juízos morais mais elevados, baseados em princípios universais, seja possível a construção de uma sociedade mais justa e democrática.

Freire nos faz refletir acerca de uma Educação Libertara, emancipatória em praticamente todo o seu legado, nos permitindo olhar para além do próprio conteúdo, mas para a esperança que ele diz, dessa forma, "A natureza esperançada da educação, por outro lado, se funda em determinadas qualidades que, constituídas no processo de formação da existência humana, algo maior do que a experiência vital, a conotam" (FREIRE, 2000, p.51).

Portanto, esperançar significa inclusive a necessidade de formarmos professores com posicionamentos políticos e que sejam críticos e que vislumbrem a emancipação do ser humano em uma sociedade mais justa e menos desigual, que perceba a importância da construção da autonomia através de uma Educação em Valores, uma Educação Libertadora, que tenha em seus principais pontos, a defesa dos Direitos Humanos.

Temos em Paulo Freire um símbolo de luta por uma educação que esteja preocupada com a integralidade do ser humano, em toda a sua complexidade e incompletude, para que possamos assim, construir um país onde se combata a desigualdade social através da ascensão pela educação e para uma educação de qualidade.

\section{Referências}

ADORNO, T. W. Educação e emancipação. Trad. Wolfgang Leo Maar. Rio de Janeiro: Paz e Terra, 1995.

BENEVIDES, M. V. Educação em Direitos Humanos: de que se trata?. São Paulo, FE-USP, 2000. (transcrição da palestra de abertura do Seminário de Educação em Direitos Humanos).

BRASIL. Constituição da República Federativa do Brasil. Brasília, DF: Senado, 1988. 
BRASIL. Ministério da educação, conselho nacional de educação. Resolução $n^{\circ} 1$, de 30 de maio de 2012. Estabelece diretrizes nacionais para a educação em direitos humanos.

CNE/CP: Diário Oficial da União, Brasília, DF, 2012.

BRASIL. Comitê Nacional de Educação em Direitos Humanos. Plano nacional de educação em direitos humanos. Brasília, DF: Secretaria de Direitos Humanos; Ministério da Educação; UNESCO, 2007. 76p.

BRASIL. Comitê Nacional de Educação em Direitos Humanos. Plano nacional de educação em direitos humanos. 2. ed. Brasília, DF: Secretaria de Direitos Humanos; Ministério da Educação; UNESCO, 2013. 73p.

BRASIL. Lei de Diretrizes e Bases da Educação Nacional. Lei nº 9.394/96, de 20 de dezembro de 1996.

BRASIL, Ministério da Educação. Parâmetros Curriculares Nacionais para o. Ensino Fundamental. Brasília, MEC/SEF. 1997.

BRASIL, Ministério da Educação. Diretrizes Curriculares Nacionais Gerais para a Educação Básica. Conselho Nacional de Educação/Câmara de Educação Básica. Resolução nº 4, de 13 de julho de 2010. Brasília: MEC, 2010.

BUXARRAIS, M. R. La formación del profesorado en educación en valores. Propuesta y materiais. Bilbao: Desclée de Brouwer, 1997

CANDAU, V. M. et al. Educação em direitos humanos e formação de professores(as). São Paulo: Cortez, 2013.

FREIRE, P. Direitos Humanos e educação libertadora: gestão democrática da educação pública na cidade de São Paulo/ Paulo Freire; organização e notas de Ana Maria Araújo Freire, Erasto Fortes Mendonça - 2a ed. - Rio de Janeiro/São Paulo: Paz e Terra, 2020.

FREIRE, P. Educação como prática da liberdade. Rio de Janeiro: Paz e Terra, 1967.

FREIRE, P. Pedagogia da indignação: cartas pedagógicas e outros escritos/ Paulo Freire. São Paulo: Editora UNESP, 2000.

FREIRE, P. Pedagogia do oprimido. Rio de Janeiro: Paz e Terra, 2005.

FREIRE, P. Pedagogia da autonomia. Coletivo Sabotagem, 2002.

FREIRE, P. Construção de uma nova cultura política. In: Poder Local, Participação Popular Construção da Cidadania. São Paulo: Fórum Nacional de Participação Popular nas administrações municipais, 1995 (N.01)

LA TAILLE, Y. Moral e ética: dimensões intelectuais e afetivas. Porto Alegre: Artmed, 2006.

LA TAILLE, Y.; MENI, M. S. S. (org.) Crise de valores ou valores em crise? Porto Alegre: Artmed, 2009.

MÉSZÁROS, I. A educação para além do capital; [tradução Isa Tavares]. - 2.ed.- São Paulo: Boitempo, 2008.

MACIEL, T. S. Educação em direitos humanos: concepções de professores de educação infantil. 2018. 201 f. Dissertação (Mestrado em Educação) - Faculdade de Filosofia e 
Ciências (FFC), Universidade Estadual Paulista “Júlio de Mesquita Filho" (UNESP), Marília, 2018.

PUIG, J. M. Ética e valores: métodos para um ensino transversal. São Paulo: Casa do Psicólogo, 1998.

RAYO, J. T. Educação em direitos humanos: rumo a uma perspectiva global. 2. ed. Porto Alegre: Artmed, 2004.

ROSTAS, M. H. S. G.; ABREU, A. K. O discurso pedagógico na ditadura militar: Educação Moral e Cívica \& currículo escolar. Educação (UFSM), Santa Maria, p. 387-398, jul. 2016. ISSN 1984-6444.

SAUL, A M.; SAUL, A. Contribuições de Paulo Freire para a formação de educadores: fundamentos e práticas de um paradigma contra-hegemônico. Educar em Revista [online]. 2016, v. 00, n. 61 [Acessado 14 Julho 2021] , pp. 19-36.

SILVA, A. M. M. Direitos humanos na educação básica: qual o significado?. In: SILVA, Ainda Maria Monteiro; TAVARES, Celma (Orgs.). Políticas e fundamentos da educação em direitos humanos. São Paulo: Cortez, 2010.

SILVA, A. M. M. Elaboração, execução e impacto do plano nacional de educação em direitos humanos: estudo de caso no Brasil. In: BRABO, Tânia Suely Antonelli Marcelino; REIS, Martha dos. Educação, direitos humanos e exclusão social. Marília: Oficina Universitária; São Paulo: Cultura Acadêmica, 2012.

SILVA, M. E. F.; BRABO, T. S. A. M.; MORAIS, A. Educação em direitos humanos e desenvolvimento moral na formação docente: a influência da religiosidade em tempos de “ideologia de gênero". Revista on line de Política e Gestão Educacional, Araraquara, v. 21, n. esp. 2, p. 1260-1282, nov., 2017.

SOUZA, L. K.. Educação para a paz e educação moral na prevenção à violência. Psicol. educ., São Paulo, v. 25, n. 2, dez., p. 131-155, 2007.

UNESCO. Organização das Nações Unidas para a Educação, a Ciência e a Cultura. Plano de Ação do Programa Mundial para Educação em Direitos Humanos - 3. ${ }^{a}$ Fase. Brasília: UNESCO/ONU/MEC/SEDH, 2015.

VENTURI, G. O universalismo ético: Kohlberg e Habermas. Democracia • Lua Nova (36) • 1995. 